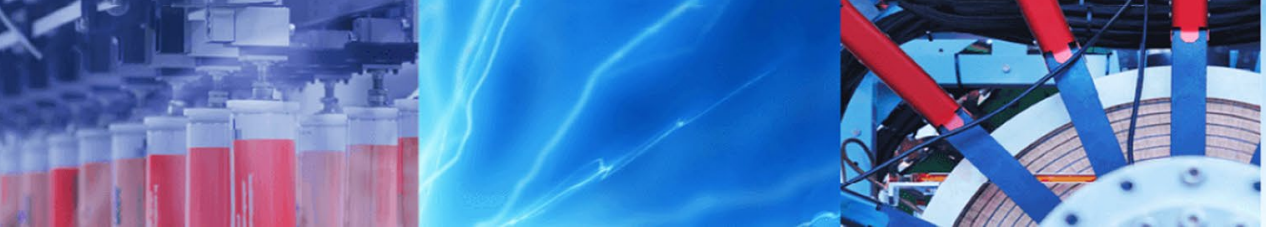

Research Article

\title{
Cost-effective $\mathrm{ZnO}-\mathrm{Eu}^{3+}$ films with efficient energy transfer between host and dopant
}

\author{
Archana Singh $^{1} \cdot$ Priyanka Arya $^{1} \cdot$ Diksha Choudhary $^{1} \cdot$ Surender Kumar $^{1} \cdot$ A. K. Srivastava ${ }^{1} \cdot$ I. B. Singh ${ }^{1}$
}

Received: 2 August 2019 / Accepted: 2 April 2020 / Published online: 10 April 2020

(c) Springer Nature Switzerland AG 2020

\begin{abstract}
The present work focuses on the deposition of Europium $\left(\mathrm{Eu}^{3+}\right)$ incorporated zinc oxide $(\mathrm{ZnO})$ film by a cost effective chemical solution deposition method. $\mathrm{ZnO}$ film with varying concentration of $\mathrm{Eu}^{3+}$ ions $(2,3$ and 4 atomic percent) were deposited and characterized using different techniques like X-ray diffractogram (XRD), scanning electron microscopy. $\mathrm{XRD}$ studies revealed that highly c-axis oriented $\mathrm{ZnO}$ films without showing any segregation of europium oxide were obtained at $650^{\circ} \mathrm{C}$. The optical properties were determined using UV-visible spectrophotometry and photoluminescence measurements. UB-visible spectroscopy revealed that $\mathrm{Eu}^{3+}$ doping shifted optical band gap with increase in transparency of the films. The $\mathrm{Eu}^{3+}$ doped film showed intense emission at $614 \mathrm{~nm}$ which was attributed to the defect emission from $\mathrm{ZnO}$ that gets trapped by $\mathrm{Eu}^{3+}$ ions ultimately leading to ${ }^{7} \mathrm{~F}_{2}$ to ${ }^{5} \mathrm{D}_{0}$ transition in $\mathrm{Eu}^{3+}$.
\end{abstract}

Keywords Thin films · Eu-doped zinc oxide · Sol-gel $\cdot$ XRD $\cdot$ Optical absorption $\cdot$ PL

\section{Introduction}

$\mathrm{ZnO}$, because of its direct wide band gap of $3.37 \mathrm{eV}$, a large exciton binding energy (60 meV) [1], superior chemical stability [2] and unique optical properties, has triggered a vast research area for both fundamental and technological reasons [3-7]. Doping in $\mathrm{ZnO}$ with selective element as well as intrinsic lattice defects greatly influence its electronic, optical and magnetic properties either in film or powder form [8-13]. Doped ZnO films have attracted much attention because of their wide applications such as photoactive material for short wavelength light emitting devices, piezoelectric transducers, optoelectronic devices and transparent conducting electrodes [14-17]. Under proper excitation conditions, $\mathrm{ZnO}$ exhibits two kinds of emissions, one is an ultraviolet (UV) near band edge emission at $380 \mathrm{~nm}$ and other is a visible deep level emission with a peak in range from 450-730 $\mathrm{nm}[18,19]$. By doping $\mathrm{ZnO}$ with luminescence centre such as trivalent rare earth elements it is possible to enlarge the palette of colors emitted by it and also to tune its emission properties, which would be greatly beneficial for light emitting device applications such as plasma display panels, multi color emission in light emitting devices [20-23]. To achieve efficient luminescence of $\mathrm{ZnO}-\mathrm{RE}^{3+}$ enhance energy transfer from semiconductor host to $\mathrm{RE}^{3+}$ is required, but due to large ionic radii difference between two and also charge mismatching results are often disappointing.

$\mathrm{ZnO}$ based films have been prepared by number of different techniques like spray pyrolysis [24], electrodeposition [8], pulsed laser deposition [25], sputtering [26], sol-gel $[11,13,27,28]$ and metal organic chemical vapor deposition method [29]. Among them, sol-gel method has distinct potential advantage over the other due to its ability to control micro structure by sol gel chemistry, highly economical and its room temperature approach. By controlling parameters like solvent nature, precursor nature and concentration, preheating temperature and time, post annealing temperature it is possible to obtain good quality thin films with good control over chemical

Archana Singh, archanas002@gmail.com| ${ }^{1}$ Advanced Materials and Processes Research Institute, Bhopal, India. 
composition, morphology and microstructure [13]. Peterson and group reported the Eu-doped $\mathrm{ZnO}$ film deposition on silicon substrate using sol-gel process, though the films deposited do not possess a good structural quality, with the accumulation of europium at the film surface. Raji et al. synthesized the $\mathrm{ZnO}-\mathrm{Eu}^{3+}$ nanostructure powder using coprecipitation method [30]. They reported that $\mathrm{Eu}^{3+}$ incorporation changed the morphology of the nanostructure from rod to flower. The energy transfer between the $\mathrm{ZnO}$ and $\mathrm{Eu}^{3+}$ was attributed to the defect mediated process. Zhang and group reported the $\mathrm{Eu}^{3+}$ doped $\mathrm{ZnO}$ nanospheres by wet chemical method [31]. They observed white emission by doping $\mathrm{Eu}^{3+}$ in $\mathrm{ZnO}$ nanospheres and showed detailed energy transfer process from $\mathrm{ZnO}$ to $\mathrm{Eu}^{3+}$. $\mathrm{Yu}$ et al. synthesized $\mathrm{ZnO}-\mathrm{Eu}^{3+}$ nanoflowers at a low temperature by hydrothermal method [32]. They reported that on excitation of $\mathrm{Eu}^{3+}$, emission showed presence of $\mathrm{Eu}^{3+}$ at different sites one of which is similar to $\mathrm{Eu}^{3+}$ in C-type $\mathrm{Eu}_{2} \mathrm{O}_{3} \cdot \mathrm{ZnO}-\mathrm{Eu}^{3+}$ doped nanostructure were prepared by combustion method. However they reported very weak visible emission intensity of $\mathrm{Eu}^{3+}$ [33].

This present work demonstrates the polymer assisted deposition of Eu-doped ZnO films using chemical solution deposition method on quartz substrate. The structural and the optical properties of the films were studied using XRD, scanning electron microscopy (SEM) and PL spectroscopy. Our results show that the deposited films possess homogeneous and uniform structure with efficient energy transfer between $\mathrm{ZnO}$ and $\mathrm{Eu}^{3+}$

\section{Experimental}

$\mathrm{Eu}^{3+}$ doped and undoped $\mathrm{ZnO}$ films were prepared on chemically cleaned quartz substrate. Biodegradable polymer polyvinyl alcohol (PVA) and zinc acetate dihydrate $\left(\mathrm{Zn}-(\mathrm{CH} 3 \mathrm{COO})_{2} \cdot 2 \mathrm{H}_{2} \mathrm{O}\right)$ were used for sol solution. To prepare a sol $1.65 \mathrm{~g}$ of Zinc acetate dehydrate (SD Fine Chemicals) and $1.65 \mathrm{~g}$ of PVA (mol. wt. 125,000, SD Fine) were added to $60 \mathrm{ml}$ of deionised water, which was then heated to $45^{\circ} \mathrm{C}$ for $1 \mathrm{~h}$ with constant stirring. For rare earth doped samples three different $\mathrm{Eu}^{3+}$ concentrations $(2,3$ and 4 at\%) were selected. Europium III nitrate (Aldrich chemicals) was used as $\mathrm{Eu}^{3+}$ source. The mixed sol was stirred continuously until all reagents were dissolved completely. The sol was then spin coated on cleaned quartz substrate at $3500 \mathrm{rpm}$ for $30 \mathrm{~s}$ and films were then dried at $120^{\circ} \mathrm{C}$ on hot plate after each coating. The above process was repeated for six times to get film of desired thickness. Finally $\mathrm{ZnO}$ films were annealed at 450,550 and $650{ }^{\circ} \mathrm{C}$ for $1 \mathrm{~h}$ in air.

Films were subjected to X-Ray diffraction studies with Cu- $\mathrm{K}_{a}$ radiation (1.54 $\AA$ ). The diffractometer (FRL XTRA,
Thermoelectron) was operated at $40 \mathrm{kV}$ and $35 \mathrm{~mA}$ with a glancing angle of $1^{\circ}$. Optical absorption study was carried out in wavelength range of $300-700 \mathrm{~nm}$ using Perkin elmer spectrometer. PL spectra were measured at room temperature with an excitation source of 325 and $465 \mathrm{~nm}$ using Fluorolog@-3, JOBIN YVON HORIBA group instrument. SEM images of samples were obtained using FEI Quanta 200, The Netherlands SEM.

\section{Result and discussion}

\subsection{Structural properties}

Structural evolution of the $\mathrm{ZnO}$ films as a function of annealing temperature was investigated by XRD analysis is shown in Fig. 1. All the patterns indicate the formation of wurtzite type $\mathrm{ZnO}$ phase with strong c-axis orientation. With the increase in annealing temperature crystallinity and orientation of films along c-axis increases. Relatively higher XRD peak intensity has been observed for samples annealed at $650^{\circ} \mathrm{C}$. The full width at half maxima (FWHM) of films also decreased with increasing temperature, which indicates that crystallinity of the films have been improved on annealing. The $c$-axis orientation in film can be explained by "survival of the fittest model" [30]; nucleation with various orientation can be formed at the initial stage of deposition and each nucleus competes to grow, but only having the fastest growth rate can survive. The small surface free energy for (002) planes [34] of $\mathrm{ZnO}$ accounts for its fastest growth at higher temperature. Therefore as annealing temperature increases films preferably grow along (002) direction.

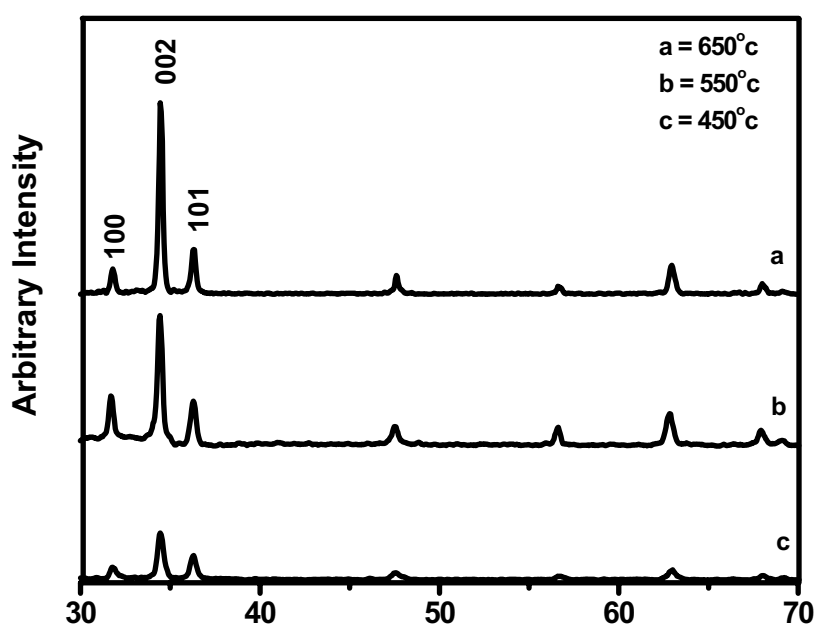

Fig. 1 X-ray diffraction pattern of pure $\mathrm{ZnO}$ films annealed at $650{ }^{\circ} \mathrm{C}(\mathrm{a}), 550^{\circ} \mathrm{C}(\mathrm{b})$ and $450^{\circ} \mathrm{C}$ (c) 
Figure $2 \mathrm{~A}$ shows the XRD pattern of films as a function of $\mathrm{Eu}^{3+}$ concentration $\left(2,3\right.$ and 4 at\%) annealed at $650{ }^{\circ} \mathrm{C}$. All films show hexagonal wurtzite structure and preferred growth along 002 plane. However preferred orientation along (002) plane decreases with increase of $\mathrm{Eu}^{3+}$ concentration. Lines due to different crystalline phases such as europium oxides or hydroxides were not detected in diffraction pattern of samples annealed at this temperature, thus suggesting homogenous dispersion of dopant in $\mathrm{ZnO}$ matrix. Higher thermal treatment of $850^{\circ} \mathrm{C}$ did not induce any change in wurtzite phase of these films however a weak peak at 2 theta $=28.4^{\circ}$ (shown in Fig. 2B) appeared. This peak was indexed as the (222) reflection of bcc structure of $\mathrm{Eu}_{2} \mathrm{O}_{3}$, similar result has also been observed in $\mathrm{Eu}^{3+}$ doped $\mathrm{ZnO}$ nanopowders [9]. This shows that high annealing condition promotes the aggregation of $\mathrm{Eu}^{3+}$ centers and crystallization of $\mathrm{Eu}_{2} \mathrm{O}_{3}$ clusters. The large lattice energy difference between $\mathrm{ZnO}(412 \mathrm{~kJ} / \mathrm{mol}$ and $\mathrm{Eu}_{2} \mathrm{O}_{3}(12,945 \mathrm{~kJ} / \mathrm{mol})$ may cause phase separation in sample at higher temperature. Tendency of rare earth element to segregate at $\mathrm{ZnO}$ grain boundary in lanthanum (La) doped $\mathrm{ZnO}$ system has already been reported $[35,36]$. Further characterizations have been carried out on films annealed at $650^{\circ} \mathrm{C}$. Inset of Fig. $2 \mathrm{~A}$ shows the XRD pattern of doped $\mathrm{ZnO}$ films in range of $33^{\circ}-35.5^{\circ}$. The diffraction pattern shows shift in 002 peaks to smaller angle with increase in $\mathrm{Eu}^{3+}$ concentration. It indicates incorporation of some of the $\mathrm{Eu}^{3+}$ ions in $\mathrm{ZnO}$ lattice although there is large ionic radii difference between $\mathrm{Zn}^{2+}(60 \mathrm{pm})$ and $\mathrm{Eu}^{3+}$ (94.7 pm) [9].

The lattice constants and volume of unit cell shows linear increase with increase in dopant concentration which is attributed to $\mathrm{Eu}^{3+}$ dopant (Fig. $3 \mathrm{~A}$ ). Eu ${ }^{3+}$ incorporation

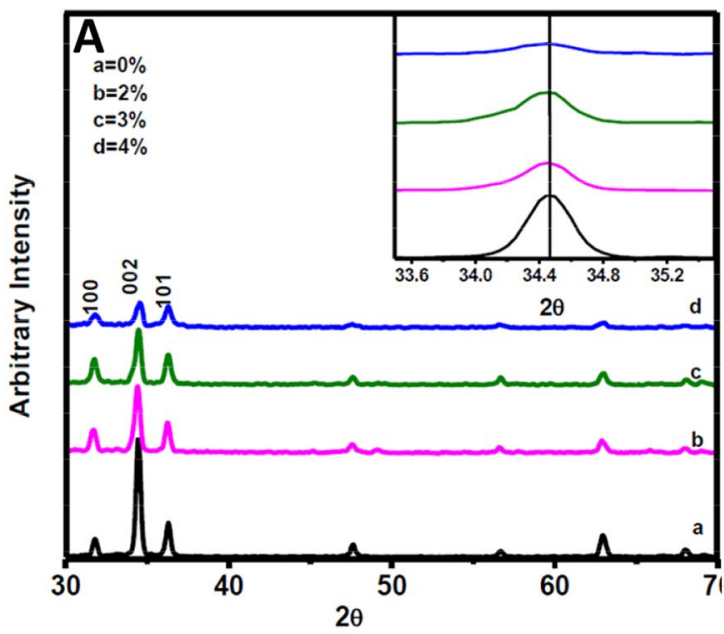

Fig. 2 a X-ray diffraction pattern of Zno films deposited using various doping concentration (at\%) of Eu annealed at $650{ }^{\circ} \mathrm{C}$ inset of shows, XRD pattern of undoped $\mathrm{ZnO}$ and Eu-doped $\mathrm{ZnO}$ films will result in expansion of $\mathrm{ZnO}$ lattice. Figure $3 \mathrm{~B}$ displays variation of FWHM of 002 diffraction peak along with mean grain size normal to 002 plane estimated by scherrer's formula. FWHM of 002 peaks become broad and increase monotonically with dopant concentration which indicates that film crystallization has deteriorated. The grain size also decreases $(85 \mathrm{~nm})$ from undoped to $(49.11 \mathrm{~nm})$ for $4 \%$ doped samples (Table 1). It has been reported that dopant with smaller ionic radii have good diffusivity and they prefer oriented growth and good crystallization but difference in ionic radii makes diffusivity of ions difficult and leads to the formation of stress in lattice [37]. In our system also due to large difference in ionic size and charge between $\mathrm{Eu}^{3+}(r=94.7 \mathrm{pm}, \mathrm{CN}=6)$ and $\mathrm{Zn}^{2+}$ $(\mathrm{r}=60 \mathrm{pm}, \mathrm{CN}=4)$ the doping of $\mathrm{Eu}^{3+}$ deteriorates crystallization of films Also segregation of $\mathrm{Eu}_{2} \mathrm{O}_{3}$ in grain boundary may inhibit the combination of $\mathrm{ZnO}$ grains and thereby decrease grain size.

Effect of doping on preferential orientation of the films was studied by calculating texture coefficient $\mathrm{TC}_{(h k)}$ for all the planes using following equation $[38,39]$.

$T C_{h k l}=\frac{I_{h k l}}{I_{0 h k l}}\left[\frac{1}{N} \sum \frac{I_{h k l}}{I_{0 h k l}}\right]$

where $\mathrm{TC}_{(h k l)}$ is the texture coefficient of $(h \mathrm{k} l)$ plane, I the measured diffraction intensity, $l_{o}$ the standard intensities measured from randomly oriented powder samples and $\mathrm{N}$ is the number of reflections observed in the X-ray diffraction pattern. The deviation of texture coefficient from unity indicates preferred orientation of the growth. Figure $3 \mathrm{C}$ shows the $\mathrm{TC}_{(h k)}$ values for typical planes of doped and undoped films which clearly imply formation of c-axis

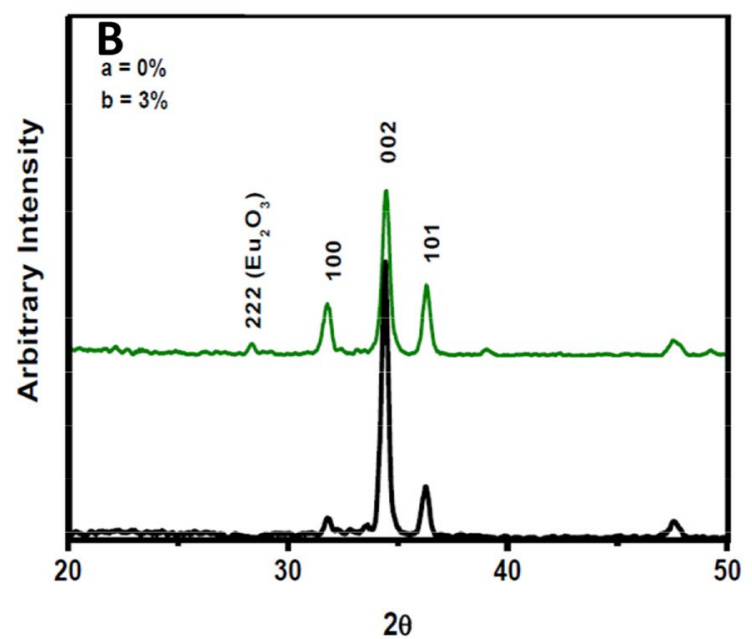

between $2 \theta$ value of $33.5^{\circ}-35.5^{\circ}$. b XRD pattern obtained for $\mathrm{ZnO}$ (a) and 3 at \% Eu-doped Zno film annealed at $850^{\circ} \mathrm{C}$ 

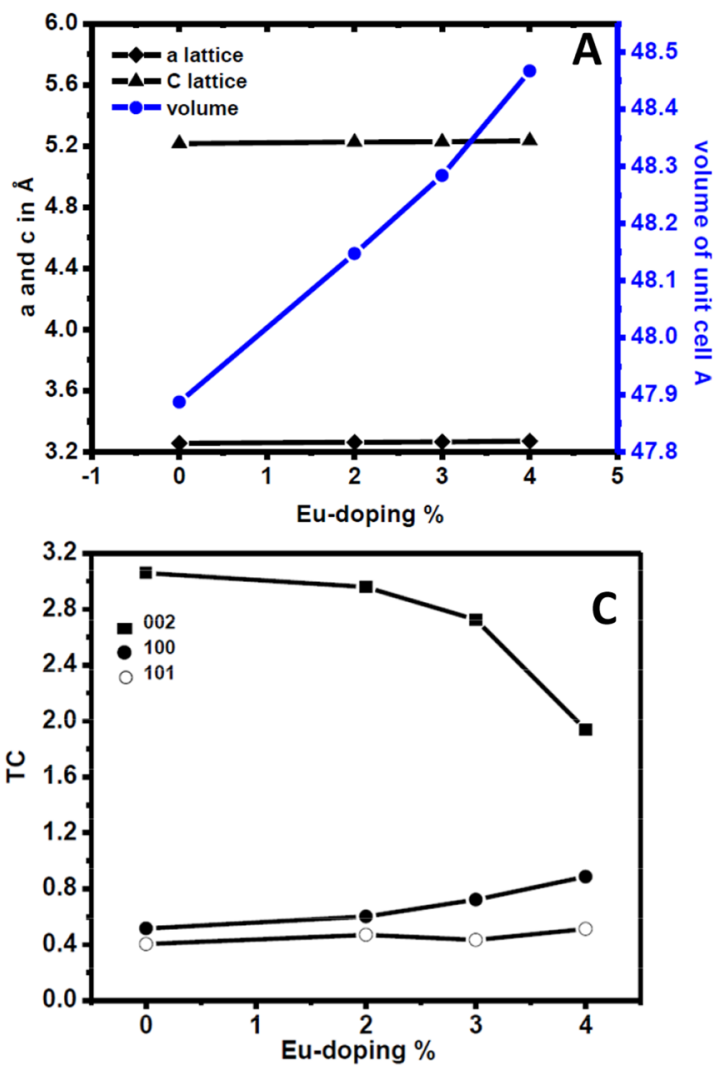

Fig. 3 a Lattice parameter ( $a$ and $c$ ) and cell volume of pure and cell volume of pure and Eu-doped Zno films. b FWHM value of (002) peak and grain size of $\mathrm{ZnO}$ films as a function of Eu-dop out concentration. c TC (002), TC (001) and TC (101) plotted against dop-
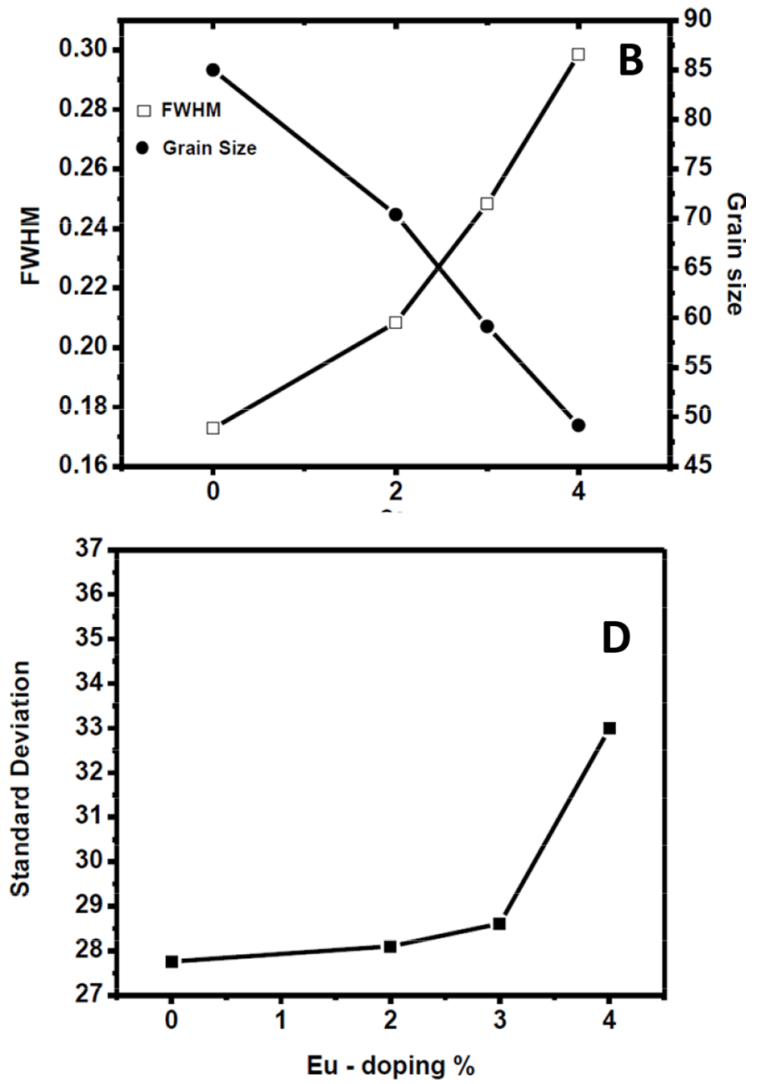

ing concentration of $\mathrm{Eu}^{3+}$ for films anneat at $650{ }^{\circ} \mathrm{C}$. d Variation of standard deviation in intensity of XRD peaks wrt doping concentration of $\mathrm{Eu}^{3+}$ for the films deposited at $650^{\circ} \mathrm{C}$
Table 1 Lattice parameters and unit cell volumes for pure and Eu incorporated $\mathrm{ZnO}$ systems

\begin{tabular}{lllllllll}
\hline Eu (at \%) & $\mathrm{a}(\AA)$ & $\mathrm{c}(\AA)$ & $\mathrm{V}(\AA)^{3}$ & Grain size $(\mathrm{nm})$ & $\mathrm{TC}_{002}$ & $\mathrm{TC}_{101}$ & $\mathrm{TC}_{100}$ & $\sigma$ \\
\hline 0 & 3.256 & 5.216 & 47.887 & 85.00 & 3.062 & 0.404 & 0.516 & 27.76 \\
2 & 3.262 & 5.225 & 48.147 & 70.40 & 2.958 & 0.470 & 0.602 & 28.61 \\
3 & 3.266 & 5.227 & 48.284 & 59.10 & 2.725 & 0.433 & 0.722 & 28.10 \\
4 & 3.270 & 5.234 & 48.467 & 49.11 & 1.939 & 0.712 & 0.839 & 32.99 \\
\hline
\end{tabular}

oriented films. However with the increase in $\mathrm{Eu}^{3+}$ concentration $\mathrm{TC}_{(002)}$ value slightly decreases but after $3 \%$ doping $\mathrm{TC}_{(002)}$ value sharply decreases that shows deviation from preferred (002) direction. Growth mechanism of the film can be studied by calculating standard deviation $(\sigma)$ using the equation [37].

$\sigma=\sqrt{\frac{\sum I_{h k l}^{2}-\left(\sum I_{(h k l)}\right)^{2} / N}{N}}$

where I stands for relative intensity of a ( $\mathrm{h} \mathrm{k} \mathrm{I)} \mathrm{plane.}$

From Fig. 3D it can be seen that there is small change in sigma values up to $3 \%$ which shows onset of homogenous nucleation up to this doping level while a relatively higher value for $4 \%$ which is attributed to deviation from preferred orientation. This may be because beyond certain doping level further heavy doping makes it difficult to form a critical nucleus to develop along a particular direction and random orientation seems to be preferred (Table 1).

Figure $4 a, b, c$ and $d$ shows surface morphology of undoped and $\mathrm{Eu}^{+3}$ doped $(2,3,4 \%) \mathrm{ZnO}$ thin films. Samples show compact, smooth and polycrystalline morphology. It can be seen that there are no cracks or peels in the films. Grain boundaries can be clearly seen. The grain size of undoped film is larger than those of $\mathrm{Eu}^{3+}$ doped films, which indicates that $\mathrm{Eu}^{3+}$ suppresses the growth of grains. Pure $\mathrm{ZnO}$ film shows a loose structure containing large 

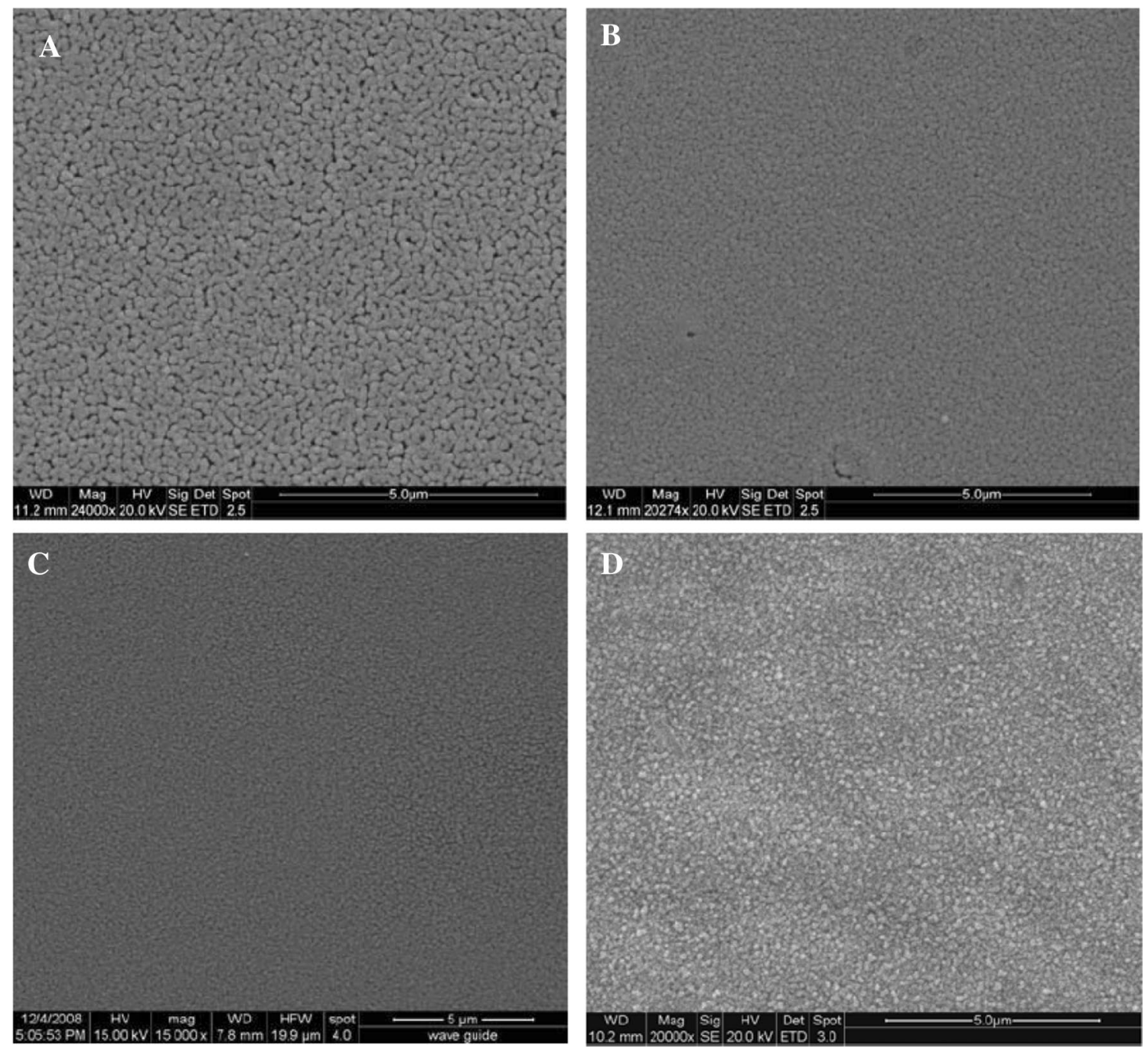

Fig. 4 SEM images f pore $\mathrm{Zn}$ and Eu-doped ZnO films with different Eu concentration; a (0\%), b (2 at\%), c (3 at\%), d (4 at\%)

grains whereas doped $\mathrm{ZnO}$ possess small grains. Small pores can also be seen in undoped film that may be due to evaporation of water while doped film shows denser and tightly packed structure. These results are consistent with XRD pattern were obtained. These SEM images imply that the surface morphology of the films is strongly dependent on the concentration of dopant.

\subsection{Optical properties}

Optical transmission spectra for undoped and doped films are shown in Fig. 5. Films are highly transparent in visible region. $\mathrm{Eu}^{3+}$ doping increased the transparency of films due to broadening of optical band gap. For optical band gap, optical absorption coefficient (a) of direct band gap semiconductor $\mathrm{ZnO}$ can be obtained by following equation [10],
$\mathrm{a}=\mathrm{A}(h n-E g)^{1 / 2}$

where $A$ is the proportionality constant, $h$ is photon energy and $E_{g}$ is optical band gap. The transmittance $T$, near the absorption edge, is given by

$\mathrm{T} \cong \exp (-\mathrm{ad})$

where $d$ is thickness of films. Also $a$ is proportional to $(\operatorname{InT})$ $[2,40,41]$

$(\ln T)^{2} \mu a^{2} d^{2}=A^{2} d^{2}\left(\left(h n-E_{g}\right)\right.$

Thus plotting $(\ln T)^{2}$ as a function of the photon energy and drawing a tangential line near the absorption edge, one can determine the optical band gap. Figure $5 b$ shows $(\operatorname{lnT})^{2}$ vs $h$ plots for undoped and doped films. The undoped $\mathrm{ZnO}$ films exhibit $E_{\mathrm{g}}$ values of $3.226 \mathrm{eV}$ while $E_{g}$ values for the 2, 3 and $4 \%$ doped $\mathrm{ZnO}$ films were found to 

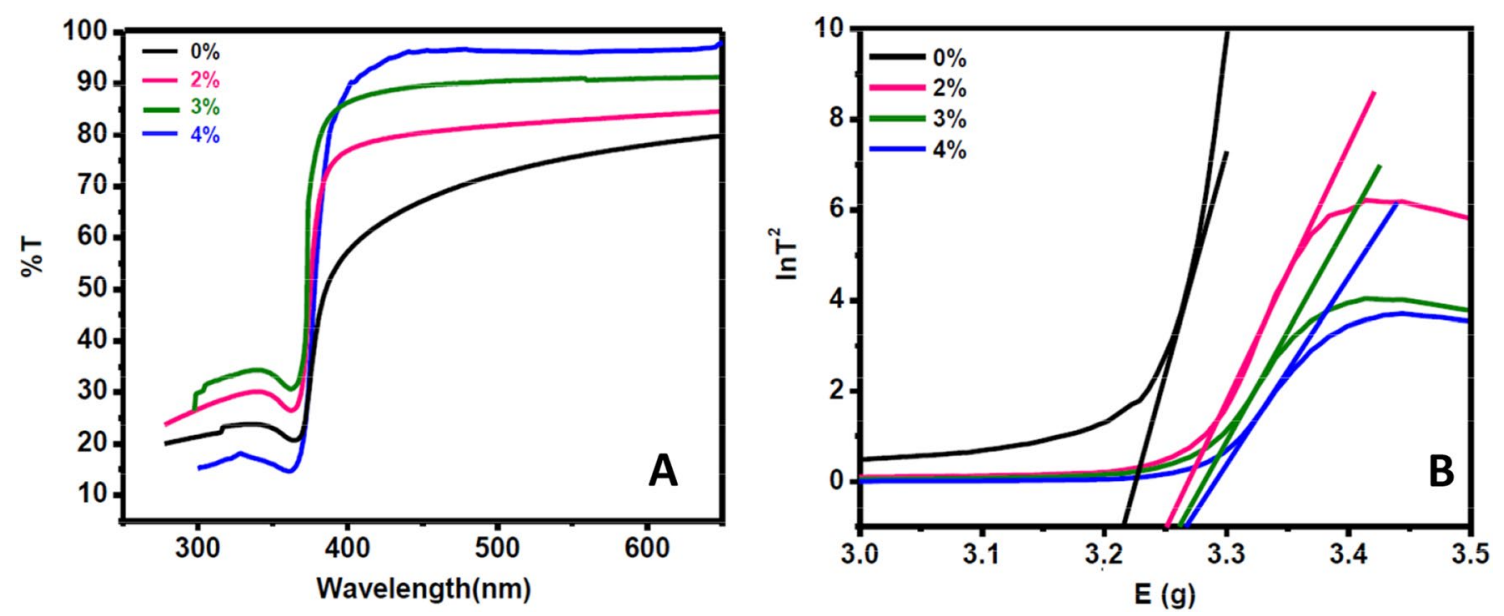

Fig. 5 a Optical transmittance of pure $\mathrm{ZnO}$, b square of $\ln \mathrm{T}(\mathrm{T}=$ transmittance) vs photon energy for undoped and doped $\mathrm{ZnO}$ films

be $3.248,3.261$ and $3.266 \mathrm{eV}$. It is clear that optical band gap increases with increase of $\mathrm{Eu}^{3+}$ concentration. The blue shift of the band gap is caused by $\mathrm{Eu}^{3+}$ ion incorporated in the $\mathrm{ZnO}$ lattice. This is consistent with $\mathrm{XRD}$ results.

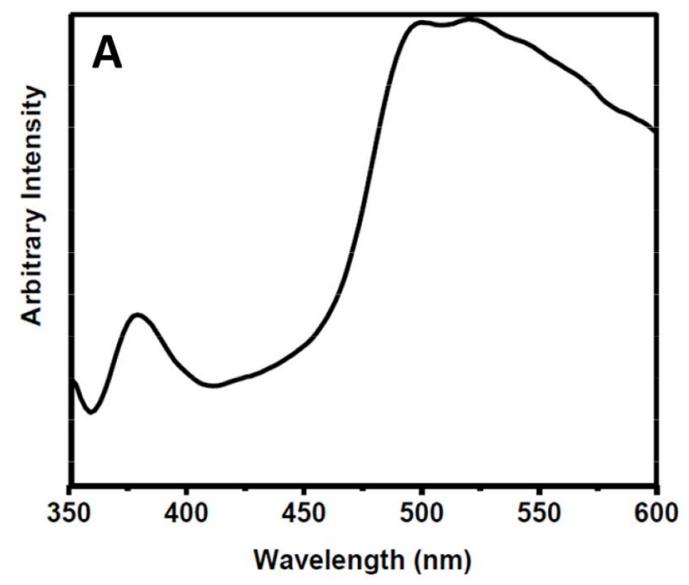

The photoluminescence ( $P L)$ of $\mathrm{ZnO}$ film was studied under an excitation of $325 \mathrm{~nm}$ (Fig. 6a). First peak is observed at $390 \mathrm{~nm}$ which is attributed to recombination of bound excitons in $\mathrm{ZnO}$. The second broad band

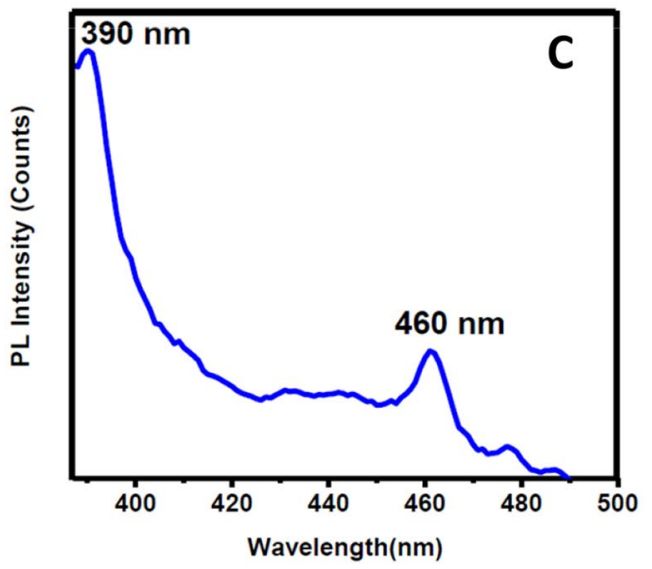

Fig. 6 a PL of ZnO film recorded at excitation of $325 \mathrm{~nm}$. b PL spectra of $2 \%$ and $3 \%$ Eu-doped ZnO films at the excitation wavelength of $464 \mathrm{~nm}$, c figure shows the PL of the $3 \%$ Eu-doped $\mathrm{ZnO}$ film annealed at $650{ }^{\circ} \mathrm{C}$ at excitation wavelength of $614 \mathrm{~nm}$ 


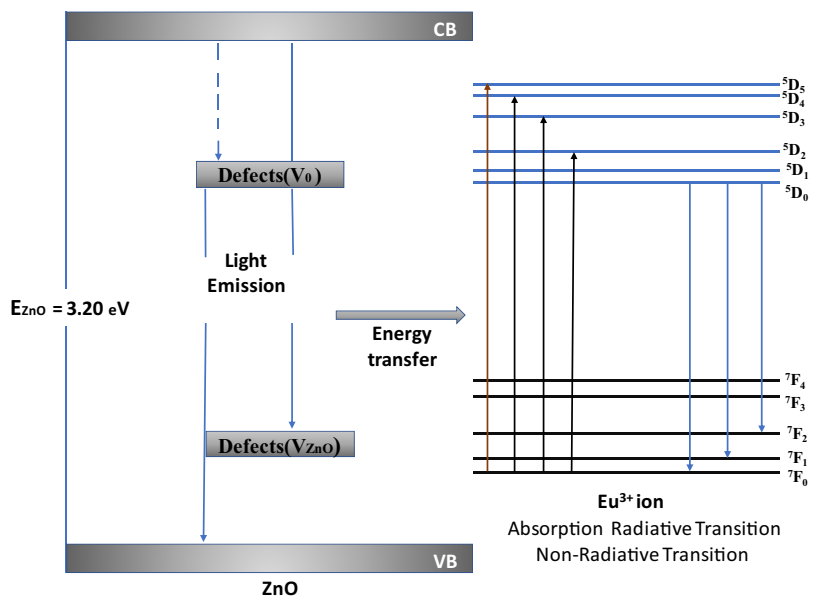

Fig. 7 Possible emission and excitation path ways in $\mathrm{ZnO}$ and Eudoped Zno

is observed at $510 \mathrm{~nm}$ which can be assigned to oxygen vacancies. Eu-doped films were studied by exciting in ${ }^{5} D_{2}$ multiplet at $464 \mathrm{~nm}$. Figure $6 \mathrm{~b}$ shows the PL spectra of 2 and $3 \%$ doped films. Emission peaks were observed at 576, $591,614,649$ and $699 \mathrm{~nm}$, which can be assigned to the transitions from the ${ }^{5} \mathrm{D}_{0}\left(\mathrm{Eu}^{3+}\right)$ excited state to the ${ }^{7} \mathrm{~F}_{\mathrm{J}}$ (with $J=0,1,2,3,4)$ multiplets, respectively. With the increase in concentration of $\mathrm{Eu}^{3+}$ intensities of peak increased [42, 43].

On absorption of excitation energy $\mathrm{ZnO}$ electrons get promoted to the conduction band from the valence band. The excited electrons get trapped by various defect sites via process of radiative decay. Now UV emission results due to the recombination of holes in the valence band with the electrons in defect states. In presence of $\mathrm{Eu}^{3+}$ in the $\mathrm{ZnO}$ lattice, a segment of recombination energy is captured by the $\mathrm{Eu}^{3+}$ ion that excites electron from the ground state of $\mathrm{Eu}^{3+}$ ion to excited state. These electron results in $\mathrm{Eu}^{3+}$ emission by radiative relaxation. This has been reported in the literature that the intensity of the $\mathrm{Eu}^{3+}$ emission depends on the charge carrier and energy transfer process. In present work, we propose that defect emission from the $\mathrm{ZnO}$ is trapped by $\mathrm{Eu}^{3+}$ ions which excite ${ }^{7} F_{\text {J }}$ to ${ }^{5} \mathrm{D}_{0}$ transition in $\mathrm{Eu}^{3+}$. These electrons get transfer from ${ }^{5} D_{j}$ state to ${ }^{7} F_{j}$ state of $\mathrm{Eu}^{3+}$ leading to light emission (Fig. 7).

Appearance of forbidden transition i.e. ${ }^{5} D_{0}$ to ${ }^{7} F_{0}$ implies that there is reduction of local symmetry around $\mathrm{Eu}^{3+}$ ions. This may be because $\mathrm{Eu}^{3+}$ ions occupy the grain boundaries of $\mathrm{ZnO}$. Now the grain boundaries have broken bonds in $\mathrm{Zn}-\mathrm{O}$ or $\mathrm{Eu}-\mathrm{O}$ and it has less $\mathrm{M}-\mathrm{O}$ coordination number. Due to this local symmetry on $\mathrm{Eu}^{3+}$ ion is reduced. Figure $6 \mathrm{~b}$ also shows that intensity of forbidden transition peak increased on increasing dopant concentration which shows further decrease of symmetric environment. Also ${ }^{5} D_{0}$ to ${ }^{7} F_{2}$ transition peak get broadened for the $4 \%$ doped films that is attributed to decreased crystal quality of films on increasing dopant concentration which is in accordance with $X R D$ results. The excitation spectra of $3 \% \mathrm{Eu}^{3+}$ doped film for $\lambda_{\text {exc }} 614 \mathrm{~nm}$ shown in Fig. 6C. As can be seen that two prominent peak at $465 \mathrm{~nm}$ for excitation ${ }^{7} \mathrm{~F}_{0}-{ }^{5} \mathrm{D}_{2}$ and a strong peak at $395 \mathrm{~nm}$ of direct ${ }^{7} \mathrm{~F}_{0}-{ }^{5} \mathrm{D}_{6}$ excitation was obtained. This peak at $395 \mathrm{~nm}$ overlaps with the emission due to $\mathrm{ZnO}$ only which is observed around $390 \mathrm{~nm}$. Similar observation was also reported for the $\mathrm{ZnO}-\mathrm{Eu}^{3+}$ nanoparticles where efficient energy transfer was reported between $\mathrm{ZnO}$ and $\mathrm{Eu}^{3+}$ [43].

$\mathrm{Y}_{2} \mathrm{O}_{3}-\mathrm{Eu}^{3+}$ and $\mathrm{YVO}_{4}-\mathrm{Eu}^{3+}$ materials are well known red emitting phosphors [44-47]. $\mathrm{YVO}_{4}-\mathrm{Eu}^{3+}$ shows a strong ${ }^{5} \mathrm{D}_{0}$ to ${ }^{7} \mathrm{~F}_{2}$ transition because of efficient energy transfer from $\mathrm{VO}_{4}{ }^{3-}$ to $\mathrm{Eu}^{3+}[45]$. Similarly $\mathrm{Y}_{2} \mathrm{O}_{3}-\mathrm{Eu}^{3+}$ shows a strong red emission from $\mathrm{Eu}^{3+}$ via $\mathrm{Eu}^{3+}-\mathrm{O}^{2-}$ charge transfer and $\mathrm{Y}^{3+}-\mathrm{O}^{2-}$ excitonic electron transfer mechanism. These oxides and systems shows $f-f$ transitions as well [46]. In $\mathrm{ZnO}-\mathrm{Eu}^{3+}$, after excitation the carriers get relaxed and are caught by defects or results in radiative emission. However the red emission from the composite involving cheap and abundant metal oxides like $\mathrm{ZnO}$ is desirable.

\section{Conclusion}

$\mathrm{Eu}^{3+}$ doped and undoped $\mathrm{ZnO}$ thin films are prepared by metal- organic decomposition method. Doping of $\mathrm{Eu}^{3+}$ does not change the wurtzite structure of $\mathrm{ZnO}$ films, however it deteriorates crystallinity of $\mathrm{ZnO}$ films and also it reduces the orientation of film along $\mathrm{c}$-axis orientation. Grain size decreases as the $\mathrm{Eu}^{3+}$ content increases in film. Doping of $\mathrm{Eu}^{3+}$ increased the transparency of films in visible region and also increase energy band gap from $3.20 \mathrm{eV}$ for undoped film to $3.23 \mathrm{eV}$ for $4 \%$ doped film, it is because of incorporation of some of the $\mathrm{Eu}^{3+}$ ion in $\mathrm{ZnO}$ film. Emission spectrum at the excitation wavelength of $464 \mathrm{~nm}$ for doped films also confirms the incorporation of $\mathrm{Eu}^{3+}$ ions in ZnO films. Excitation spectrum shows the efficient energy transfer between $\mathrm{ZnO}$ and $\mathrm{Eu}^{3+}$.

Acknowledgements The authors acknowledge the director CSIRAMPRI, for allowing to carry out the project. One of the authors A.S acknowledge the INSPIRE faculty award (IFA13CH112) and Alexander Humboldt Foundation for the AVH postdoctoral fellowship for the financial assistance.

\section{Compliance with ethical standards}

Conflict of interest The author(s) declare that they have no competing interests. 


\section{References}

1. Ahmed S, Szymanski P, El-Nadi L (2014) Energy-transfer efficiency in Eu-doped $\mathrm{ZnO}$ thin films: the effects of oxidative annealing on the dynamics and the intermediate defect states. ACS Appl Mater Interfaces 6(3):1765-1772. https://doi. org/10.1021/am404662k

2. Konenkamp R, Word R, Godinez M (2005) Ultraviolet electroluminescence from $\mathrm{ZnO} /$ polymer heterojunction light-emitting diodes. Nanoletter 10:2005-2008. https://doi.org/10.1021/nl051 $501 r$

3. Ozgur U, Alivov Y, Teke A, Reschikoy M, Dogan S, Avrutin V, Cho S, Morkoc $\mathrm{H}$ (2005) A comprehensive review of $\mathrm{ZnO}$ materials and devices. J Appl Phys 98:41301. https://doi.org/10.1063/1.19926 66

4. Che P, Meng J, Guo L (2007) Oriented growth and luminescence of ZnO:Eu films prepared by sol-gel process. J Lumin 122:168171. https://doi.org/10.1016/j.jlumin.2006.01.076

5. Kossanyi J, Kouyate D, Pouliquen J, Ronfard-Haret J, Valat $P$, Oelkrug D, Mammel U, Kelly G, Wilkinson F (1990) Photoluminescence of semiconducting zinc oxide containing rare earth ions as impurities. J Lumin 46:17-24. https://doi.org/10.1016/00222313(90)90077-O

6. Kouyate D, Ronfard-Haret J, Kossanyi J (1991) Photo- and electro-luminescence of rare earth-doped semiconducting zinc oxide electrodes: emission from both the dopant and the support. J Lumin 50:205. https://doi.org/10.1016/00222313(91)90044-V

7. Yoon K, Cho J (2000) Photoluminescence characteristics of zinc oxide thin films prepared by spray pyrolysis technique. Mater Res Bull 35:39-46. https://doi.org/10.1016/S0025 -5408(00)00183-5

8. Pauporte T, Pelle F, Viana B, Aschehoug P (2007) Luminescence of nanostructured $\mathrm{Eu}^{3+} / \mathrm{ZnO}$ mixed films prepared by electrodeposition. J Phys Chem C 111:15427-15432. https://doi. org/10.1021/jp0747860

9. Armelao L, Bottaro G, Pascolini M, Sessolo M, Tondello E, Bettinelli M, Speghini A (2008) Structure-luminescence correlations in europium-doped sol-gel $\mathrm{ZnO}$ nanopowders. J Phys Chem C 112:4049-4054. https://doi.org/10.1021/jp710207r

10. Fujihara S, Ogawa Y, Kasai A (2004) Tunable visible photoluminescence from $\mathrm{ZnO}$ thin films through $\mathrm{Mg}$-doping and annealing. Chem Mater 16:2965-2971. https://doi.org/10.1021/cm049 $599 i$

11. Zhang Y, Zhang Z, Lin B, Fu Z, Xu J (2005) Effects of Ag doping on the photoluminescence of $\mathrm{ZnO}$ films grown on $\mathrm{Si}$ substrates. J Phys Chem B 109(41):19200-19203. https://doi.org/10.1021/ jp0538058

12. Han S, Jang T, Kim Y, Park B, Park J, Jeong Y (2004) Exchange bias and the origin of magnetism in Mn-doped $\mathrm{ZnO}$ tetrapods. Appl Phys Lett 85:2589-2595. https://doi.org/10.1063/1.1795366

13. Petersen J, Brimont C, Gallart M, Schmerber G, Gilliot P, U-Bouillet C, Rehspringer J, Coils S, Becker C, Slaoui A, Dinia A (2010) Correlation of structural properties with energy transfer of Eu-doped $\mathrm{ZnO}$ films prepared by sol-gel process and magnetron sputtering. J Appl Phys 107:123522-123530. https://doi. org/10.1063/1.3436628

14. Thomas D (1960) The exciton spectrum of zinc oxide. J Phys Chem Solids 16:86-96. https://doi.org/10.1016/00223697(60)90104-9

15. Joseph M, Tabata H, Kawai T (1999) Ferroelectric behavior of Lidoped $\mathrm{ZnO}$ thin films on $\mathrm{Si}(100)$ by pulsed laser deposition. Appl Phys Lett 74:2534-2540. https://doi.org/10.1063/1.123889

16. Perez-casero R, Gutierrez-Llorente A, Mollwilfrid O, Defourneau S, Defourneau D (2005) Er-doped ZnO thin films grown by pulsed-laser deposition. J Appl Phys 97:054905-054911. https ://doi.org/10.1063/1.1858058

17. Armelao $L$, Heigl F, Jurgensen $A$, Blyth $R$, Regier $T$, Zhou $X$, Sham $\mathrm{T}$ (2007) X-ray excited optical luminescence studies of $\mathrm{ZnO}$ and Eu-doped ZnO nanostructures. J Phys Chem C 111:1019410201. https://doi.org/10.1021/jp071379f

18. Kar S, Dev A, Chaudhuri S (2006) Simple solvothermal route to synthesise $\mathrm{ZnO}$ nanosheets, nanonails and well aligned nanorod arrays. J Phys Chem B 110:17848-17853. https://doi. org/10.1021/jp0629902

19. Nyffenegger R, Craft B, Shaaban M, Gorer S, Erley G, Penner $R$ (1998) A hybrid electrochemical/chemical synthesis of zinc oxide nanoparticles and optically intrinsic thin films. Chem Mater 10:1120-1129. https://doi.org/10.1021/cm970718m

20. Gao S, Zhang H, Deng R, Wang X, Sun D, Zheng G (2006) Engineering white light-emitting Eu-doped $\mathrm{ZnO}$ urchins by biopolymer-assisted hydrothermal method. Appl Phys Lett 89:123125123132. https://doi.org/10.1063/1.2357031

21. Chen L, Zhang J, Zhang X, Liu F, Wang X, (2008) Optical properties of trivalent europium doped $\mathrm{ZnO}: \mathrm{Zn}$ phosphor under indirect excitation of near-UV light. Opt Express 16(16):1179511801. https://doi.org/10.1364/OE.16.011795

22. Lima SAM, Sigoli FA, Davolos MR, Jafelicci M Jr (2002) Europium (III)-containing zinc oxide from Pechini method. J Alloys Compd 344(1):280-284. https://doi.org/10.1016/S0925-8388(02)00369 $-9$

23. Abdullah M, Morimoto T, Okuyama K (2003) Generating blue and red luminescence from $\mathrm{ZnO} /$ poly(ethylene glycol) nanocomposites prepared using an in-situ method. Adv Funct Mater 13(10):800-804. https://doi.org/10.1002/adfm.200304330

24. Pauporte T, Goux A, Kahn-Harari A, de Tacconi N, Chenthamarakshan R, Rajeshwar K, Lincot D (2003) Cathodic electrodeposition of mixed oxide thin films. J Phys Chem Solids 64(9):1737-1742. https://doi.org/10.1016/S0022-3697(03)00122-7

25. Lorenz M, Wagner G, Rahm A, Schmidt H, Hochmuth H, Schmid H, Mader W, Brandt M, Von Wenckstern H, Grundmann H (2008) Homoepitaxial ZnO thin films by PLD: structural properties. Phys Status Solidi (C) 5(10):3280-3287. https://doi.org/10.1002/ pssc.200779504

26. Säuberlich F, Fritsche J, Hunger R, Klein A (2003) Properties of sputtered $\mathrm{ZnO}$ films and its interfaces with CdS. Thin Solid Films 431:378-381. https://doi.org/10.1016/S0040-6090(03)00251-7

27. Fujihara S, Suzuki A, Kimura T (2003) Ga-doping effects on electrical and luminescent properties of $\mathrm{ZnO}$ :(La, Eu)OF red phosphor thin films. J Appl Phys 94(4):2411-2416. https://doi. org/10.1063/1.1594817

28. Chen P, Ma X, Yang D (2007) ZnO:Eu thin-films: Sol-gel derivation and strong photoluminescence from ${ }^{5} \mathrm{D}_{0} \rightarrow{ }^{7} \mathrm{~F}_{0}$ transition of $\mathrm{Eu}^{3+}$ ions. J Alloys Compd 431(1):317-320. https://doi. org/10.1016/j.jallcom.2006.05.078

29. Kasuga M, Takano T, Akiyama S, Hiroshima K, Yano K, Kishio K (2005) Growth of ZnO films by MOCVD in high magnetic field. J Cryst Growth 275(1):1545-1550. https://doi.org/10.1016/j.jcrys gro.2004.11.189

30. Raji R, Akhilesh Kumar RG, Gopchandran KG (2019) Influence of local structure on luminescence dynamics of red emitting ZnO-Eu3+ nanostructures and its JuddOfelt analysis. J Lumin 205:179-189. https://doi.org/10.1016/j.jlumin.2018.09.002

31. Zhang Y, Liu Y, Wu L, Xie E, Chen J (2009) Photoluminescence and $\mathrm{ZnO} \rightarrow \mathrm{Eu}^{3+}$ energy transfer in $\mathrm{Eu}^{3+}$-doped $\mathrm{ZnO}$ nanospheres. J Phys D: Appl Phys 42:085106-108519. https://doi. org/10.1088/0022-3727/42/8/085106

32. Cheng B, Yu L, Chang-Kui D, Wang H, Tanner PA (2008) Vacuum ultraviolet and visible spectra of $\mathrm{ZnO}: \mathrm{Eu}^{3+}$ prepared by combustion synthesis. J Phys: Condens Matter 20:34523-34530. https:// doi.org/10.1088/0953-8984/20/34/345231 
33. Zeng X, Yuan J, Wang J, Zhang J (2012) Ferromagnetism in Tb doped ZnO nanocrystalline films. J Appl Phys 111:113704113711. https://doi.org/10.1063/1.4720381

34. Yu X, Ma J, Ji F, Wang Y, Zhang X, Cheng C, Ma H (2005) Investigation on doping dependency of solution-processed Ga-doped ZnO thin film transistor. J Cryst Growth 274:474-480. https:// doi.org/10.1063/1.2976309

35. Fujimura N, Nishihara T, Goto S, Xu Jand Ito T (1993) The effects of Xe on an rf plasma and growth of $\mathrm{ZnO}$ films by $\mathrm{rf}$ sputtering. J Cryst Growth 130:269-276. https://doi.org/10.1063/1.1682682

36. Bachir S, Sandouly C, Kossanyi J, Ronfard-Haret JC (1996) Selective enhancement of blue electroluminescence from GaN:Tm. J Phys Chem Solids 5:1869-1875. https://doi.org/10.1063/1.12495 8

37. Jadwisienczak W, Lozykowski H, Xu A, Patel B (2002) Visible emission from $\mathrm{ZnO}$ doped with rare-earth ions. J Electron Mater 31:776-784

38. Fujihara S, Sasaki C, Kimura T (2001) Effects of Na content on the luminescence behavior, conduction type, and crystal structure of Na-doped ZnO films. J Eur Ceram Soc 21:2109-2118. https:// doi.org/10.1063/1.3603033

39. Barret C, Massalaski J (1980) Structure of metals. Pergaron press, Oxford, p 1923

40. Deokate R, Pawar S, Moholkar A, Sawant V, Pawar C, Bhosale C, Rajpure K (2008) Effect of trisodium citrate concentration on the structural and photodiode performance of $\mathrm{CdO}$ thin film. Appl Surf Sci 254:2187-2195. https://doi.org/10.1016/j.apsus c.2007.09.006

41. Zhou H, Li Z (2005) Synthesis of nanowires, nanorods and nanoparticles of $\mathrm{ZnO}$ through modulating the ratio of water to methanol by using a mild and simple solution method. Mater Chem Phys 89:326-331. https://doi.org/10.1016/j.matchemphy s.2004.09.006
42. Hu J, Gordan RG (1992) Deposition of boron doped zinc oxide films and their electrical and optical properties. J Electrochem Soc 139:2014-2022. https://doi.org/10.1149/1.2221166

43. Gerigk M, Ehrenreich $P$, Wagner MR, Wimmer I, Reparaz JS, Sotomayor Torres CM, Schmidt-Mende L, Polarz S (2015) Nanoparticle shape anisotropy and photoluminescence properties: Europium containing ZnO as a model case. Nanoscale 7:1696916982. https://doi.org/10.1039/C5NR02550H

44. Han N, Gao X, Lu G, Zeng D, Wan X, Tie S, Lan S (2017) Novel rod$\mathrm{Y}_{2} \mathrm{O}_{3}: \mathrm{Eu}^{3+} @ 0.01 \mathrm{YVO} 4: \mathrm{Eu}^{3+}$ with open core/shell nanostructure and "off-and-on" fluorescent performance. RSC Adv 7:5295552961. https://doi.org/10.1039/C7RA08905H

45. Wang F, Xue X, Liu X (2008) Multicolor tuning of (Ln, P)-doped YVO4 nanoparticles by single-wavelength excitation. Angew Chem Int Ed Engl 47:906-909. https://doi.org/10.1002/ anie.200704520

46. Engelsen D, Fern GR, Ireland TG, Harris PG, Hobson PR, Lipman A, Dhillon R, Marsha PJ, Silver J (2016) Ultraviolet and blue cathodoluminescence from cubic $\mathrm{Y}_{2} \mathrm{O}_{3}$ and $\mathrm{Y}_{2} \mathrm{O}_{3}: \mathrm{Eu}^{3+}$ generated in a transmission electron microscope. J Mater Chem C 4:70267034. https://doi.org/10.1039/C6TC01750A

47. Wang W, Cheng Z, Yang P, Hou Z, Li C, Li G, Dai Y, Lin J, (2011) Patterning of $\mathrm{YVO}_{4}: \mathrm{Eu}^{3+}$ Luminescent films by soft lithography. Adv Funct Mater 21:456-463. https://doi.org/10.1002/adfm.20100 1467

Publisher's Note Springer Nature remains neutral with regard to jurisdictional claims in published maps and institutional affiliations. 